\title{
You Get What You (don't) Pay for: The Impact of Volunteer Labour and Candidate Spending at the 2010 British General Election ${ }^{1}$
}

\section{Justin Fisher ${ }^{1, *}$, Ron Johnston ${ }^{2}$, David Cutts ${ }^{3}$, Charles Pattie ${ }^{4}$ and Edward Fieldhouse 5}

${ }^{1}$ Magna Carta Institute, Brunel University, Uxbridge, UK;

${ }^{2}$ School of Geographical Sciences, University of Bristol, Bristol, UK;

${ }^{3}$ Department of Politics, Languages \& International Studies, University of Bath, Bath, UK;

${ }^{4}$ Department of Geography, University of Sheffield, Sheffield, UK;

5 Institute for Social Change, University of Manchester, Manchester, UK

*Correspondence: justin.fisher@brunel.ac.uk

\begin{abstract}
Repeated evidence in Britain demonstrates the positive electoral payoffs from constituency campaigning. However, the impact of such campaigning varies depending upon the electoral context and the effectiveness of campaign management. Debate also exists in respect of the relative impact of traditional versus more modern campaign techniques, as well as between campaign techniques that incur cost and those that are carried out voluntarily. Such debates are of interest not only to academics and political parties, but also to regulators when considering whether to restrict campaign spending in the interests of electoral parity. This article uses candidate spending data and responses to an extensive survey of election agents at the British General Election of 2010 to assess the impact of both campaign expenditure and free, voluntary labour on electoral performance. It suggests that both have some independent impact, but that impact varies by party. The implications of these results are highly significant in both academic and regulatory terms - campaign expenditure can affect electoral outcomes but these effects are offset to some extent by voluntary efforts.
\end{abstract}

There is now a large body or research which demonstrates over a series of elections that campaigning at district (constituency) level in Britain can produce electoral payoffs (Whiteley and Seyd, 1994; Pattie et al., 1995; Denver and

\footnotetext{
${ }^{1}$ Research for this article was funded by the Economic and Social Research Council (grant number RES-000-22-2762). This support is gratefully acknowledged.
} 
Hands, 1997; Denver et al., 2003; Clarke et al., 2004, 2009; Fieldhouse and Cutts, 2008; Fisher et al., 2011). The level of payoffs varies. For example, Fisher et al. (2011) show that there are four key variables exogenous to a constituency which impact upon the effectiveness of campaigning: the closeness of the election at national level, the likelihood of a significant change in parties' standing, the number of target seats and the extent to which central parties have clear objectives in respect of their campaign management. Equally, Pattie et al. (1995) have shown that the effectiveness of candidate campaign spending varies depending upon whether a candidate is an incumbent or a challenger, reflecting the work of Gary Jacobson (1980) in the USA, and Pattie and Johnston (2009) have shown that the payoffs are less for government parties than for their opponents. Overall, however, different research teams, using different data have arrived at broadly the same conclusion-campaigning at the district level can influence electoral outcomes.

The two principal approaches to the measurement of campaign intensity as a means to assess electoral effects use different data sources, which are brought together for this article. The first uses candidate spending data as a surrogate for campaign intensity. ${ }^{2}$ The second employs a survey of election agents ${ }^{3}$ designed to capture the many different aspects of campaigns: preparation, organisation, manpower, use of computers, polling day activity, use of telephones, use of direct mail, canvassing, use of leaflets and e-campaigning (Fisher et al., 2011: 827). Critically, this includes both campaign techniques that incur financial cost, but also those that are provided free by volunteers. Both approaches have advantages and disadvantages. The agent survey is a much more direct measure of campaign intensity than campaign spending, and captures a very wide range of activities. However, it is potentially limited by response rates. That said, the 2010 survey solicited a very respectable response rate of $54 \%$. And the responses to the survey were in fact strongly representative, both in terms of the electoral status of the seats and when comparing them with the percentage of maximum spend by candidates during the regulated 'Long' and 'Short' campaigns-see Appendix Tables A1 and A2. The analysis of candidate spending is not constrained by response rates. Declaration of spending is required by law and the returns are published by the Electoral Commission. Thus, near complete

\footnotetext{
${ }^{2}$ Candidate spending in Britain is limited by law and that limit varies by the electorate and geography of the constituency. Thus, the appropriate measurement of candidate spending is not the total expenditure, but the percentage of the maximum permitted.

${ }^{3}$ All candidates are legally obliged to retain an election agent. The agent is responsible for the organisation and conduct of the campaign. This survey is sent to election agents of all candidates in Great Britain from the Conservative Party, the Labour Party, the Liberal Democrats, Plaid Cymru and the Scottish National Party standing for election to the Westminster Parliament.
} 
spending data are available for almost all candidates across a long run of elections. However, campaign spending focuses on the material aspects of the campaign (most money is spent on printed material such as leaflets), and cannot properly capture volunteer effort. Notwithstanding, previous studies (Denver and Hands, 1997; Johnston and Pattie, 2006) have shown a fairly strong relationship between the level of candidate spending and the wider level of campaign intensity (as captured through the survey). And Fieldhouse and Cutts (2008) show that in 2005, both spending and the agent survey intensity index tapped the same underlying latent construct or campaign effort. In 2010, spending again correlated with overall campaign intensity, but not perhaps as strongly as one might expect. For example, correlating the candidate expenditure over the period from the dissolution of Parliament to polling day (the 'Short campaign') with overall campaign intensity produces correlation coefficients $(r)$ of $0.618,0.732$ and 0.716 for the Conservatives, Labour and Liberal Democrats, respectively. Candidate spending captures a significant proportion of campaign intensity, but clearly not all of it.

\section{Candidate spending}

The fact that candidate spending fails to capture a significant proportion of campaign efforts matters not only in academic terms, but also in regulatory ones. Candidate expenditure has been limited by law in Britain since 1883-a move designed both to limit any potential electoral benefit arising from a larger financial endowment and also to limit the cost of elections themselves (Clift and Fisher, 2004). However, despite this longstanding regulation, significant concerns have been raised in recent years about the electoral impact of spending outside the regulatory period. Johnston and Pattie (2007) have shown, for example, that Conservative spending at the district level in advance of the 2005 election did indeed yield electoral payoffs, while more recent work by Cutts et al. (2012) shows that this was also the case in 2010. As a result of such concerns, the regulated period was extended in the 2010 election. In addition to the period from dissolution to polling day (a period of between 3 and 6 weeks at recent elections) - the 'Short campaign'-legislation introduced in 2009 introduced a second regulated period of limited candidate spending-from 1 January 2010 to the dissolution (a period of just over three months): the 'Long campaign'. Despite this introduction, concerns have remained about the ability of the currently financially dominant Conservatives to gain an electoral advantage on account of their greater spending power. Table 1 illustrates the Conservatives' advantage. On average, Conservative candidates were able to spend $66.7 \%$ of the legal maximum in the Short campaign period, compared with 51 and $37.4 \%$ for Labour and the Liberal Democrats respectively. 
Table 1. Mean maximum of permitted candidate expenditure in $2010(n=621)$

\begin{tabular}{llll}
\hline$\%$ & Conservative & Labour & Lib Dems \\
\hline Short campaign & 66.7 & 51.0 & 37.4 \\
Short + Long campaign & 38.2 & 25.6 & 19.6 \\
\hline
\end{tabular}

Combining the spending in both regulated periods (the Long and the Short campaign) again shows a fairly substantial Conservative advantage.

However, despite the Conservative financial advantage overall, the electoral advantages were less clear cut. At both national and district levels, the extra spending power was not matched by electoral gains to the same degree (Fisher, 2010; Johnston et al., Forthcoming). What accounts for this apparent anomaly? First, of course, it could be that the Conservatives spent their money unwisely and that other parties targeted resources more effectively. One way to test this is to assess the level of spending depending upon the electoral status of a seat. Although the unit of analysis is campaigning at the district level, all parties seek to coordinate their district level campaigns from the centre. This level of centralisation has been increasing over time (Fisher and Denver, 2008) and has yielded electoral payoffs (Fisher et al., 2006). Thus, central parties designate whether or not seats are targets. This exercise is more than cosmetic. Target seats receive more in the way of assistance from the central party, through the provision, for example, of staff and also through telephone and direct mail campaigning run from the centre.

As a result of such coordination, broadly speaking, we would expect a party's national and regional organisations to ensure that their local parties-which are responsible for raising almost all of the money spent on the constituency campaigns - to be more active raising funds in their target seats (seats which it was seeking to gain, or its own seats which the party regarded as being vulnerable) and least in the seats where it had no chance of winning. In seats which a party holds, but where there is little chance of defeat, we would expect levels of spending to be somewhere in between. ${ }^{4}$ Table 2 examines whether this is the case. ${ }^{5}$ As we can see, the patterns of candidate spending were much as predicted with the Conservatives on average outspending their two opponents in all seat categories

\footnotetext{
${ }^{4}$ In 2010, the context for designating target seats was a little uncertain on account of extensive boundary reviews in England and Wales following the 2005 election. Thus, both parties and indeed academics made use of notional results in England and Wales for 2005.

${ }^{5}$ Seat categories in terms of electoral status are determined by the central parties. Thus, in the 2010 election, all existing Liberal Democrat seats were regarded as targets. As a result, there are no seats in the Held not Target category.
} 
Table 2. Candidate spending by electoral status $(n=621)$

\begin{tabular}{llll}
\hline Short (Short + Long) & Held not Target & Target & Not Held not Target \\
\hline Conservative & $78.4(39.1)$ & $88.7(64.2)$ & $44.1(21.4)$ \\
Labour & $65.7(27.9)$ & $78.9(51.1)$ & $23.7(9.7)$ \\
Liberal Democrat & $\mathrm{n} / \mathrm{a}$ & $88.7(63.2)$ & $27.7(11.4)$ \\
\hline
\end{tabular}

Note: Figures represent the percentage spent on the maximum permitted expenditure.

both in the Short campaign and in the two campaigns combined. The only particular surprise is that Conservative spending was relatively high in both its safe seats (labelled Held not Target) and in seats where the party had very little chance of electoral success (labelled not Held not Target). This relative lack of differentiation is a function in part of this three-category table. The categories do not, for example, discriminate between degrees of marginality within the categories, and Johnston et al. (Forthcoming) show that there is a clear relationship between marginality and levels of spending. However, the central parties' target lists do not tally entirely with marginality (though there is a link). Thus, while the table may understate the differentiation between categories a little, the central point remains that the differentiation between targets and non-targets for the Conservatives was weaker than might have been expected.

A second possibility is that, overall, parties' campaigns were differentially effective on account of campaign management. These were the conclusions of Fisher et al. (2011), who show that despite the exogenous contextual circumstances being unfavourable to Labour, the party was successful in boosting its vote through campaigning by having clear objectives about the desired outcome of the election. Labour knew it was likely to lose and so its strategy was to minimise Conservative gains in order to deny the party a parliamentary majority. This entailed effectively sacrificing some seats won by only small margins in 2005, which were likely to be won by the Conservatives in 2010, in order to focus resources to those seats that, if held, would deny the Conservatives a majority. By way of contrast, the Conservatives focused too much attention on seats that the party would win anyway.

A third possibility is that candidate expenditure does not capture all the key aspects of campaigning sufficiently well. A reliance on this measure alone as an indicator of campaign intensity therefore has the potential to generate a misleading picture. To be sure, many aspects of campaigning do require expenditure (notably on the printing of leaflets, posters and other media which is what the bulk of the reported expenditure goes on: Johnston et al., 2011), and these will be captured by candidate spending. But given that many aspects of campaigning 
Table 3. Mean free campaign indicators by party

\begin{tabular}{lccc}
\hline & Conservative & Labour & Lib Dems \\
\hline \% electorate canvassed & 26 & 16 & 10 \\
\% of constituency covered by number takers & 33 & 16 & 17 \\
No. of polling day workers & 88 & 42 & 46 \\
N & 287 & 388 & 353 \\
\hline
\end{tabular}

rely on labour and cannot legally be undertaken by paid staff, but can be carried out by unpaid volunteers, there is the possibility that parties can counteract the effects of differential wealth through the efforts of unpaid volunteers engaged in a whole range of activities including canvassing, and polling day activities such as 'knocking-up' to ensure that a party's identified supporters remember to vote. Again, the effectiveness of these activities will depend both on their aggregate levels, and how efficiently the efforts of volunteers are distributed. This then, is the focus of this article. To what extent does 'free campaigning', independent of that which incurs cost, make a separate contribution to parties' electoral performance at the district level?

\section{Free campaigning}

The survey of election agents provides some useful data with which to address this issue, featuring three questions which broadly capture the 'free' aspects of election campaigns. They cover the proportion of the electorate canvassed on the doorstep during a campaign; the proportion of the constituency covered by volunteers staffing polling stations to take details of who had voted and the number of polling day workers. Table 3 illustrates the relative strength of each party in respect of these free activities. Across every indicator, the Conservatives had a significant advantage-double that of their competitors in some instances. However, as with any resource, the aggregate total only tells us so much. What is more important is where that resource is utilised and how effectively.

To get a better indication of the distribution of 'free' campaign effort, it is more useful to produce a scale of the above items. This is done through principal components analysis. ${ }^{6}$ All three variables load on a single factor as one might expect (for the full solution, see Appendix Table A3). These scores were then standardised around a mean of 100 to permit ease of interpretation.

\footnotetext{
${ }^{6}$ Where there were missing data on individual variables that formed part of these scales, multiple imputation was used, which took account of the individual party and the target status of the seat.
} 
Table 4. Mean free campaigning effort by electoral status

\begin{tabular}{lrlll}
\hline & All & Held not Target & Target & Not Held not Target \\
\hline Conservative $(n=287)$ & 118 & 132 & 135 & 96 \\
Labour $(n=388)$ & 95 & 108 & 109 & 80 \\
Liberal Democrat $(n=353)$ & 92 & $n / a$ & 128 & 86 \\
\hline
\end{tabular}

Table 4 illustrates the distribution of free resources by the electoral status of the seat. Here, we might expect a more efficient distribution of effort than is the case with candidate spending as the amount of volunteer activity is not capped. However, often frustratingly for parties, human resources may actually be less mobile than financial ones (Fisher and Denver, 2008). And so the picture is mixed. On the one hand, the level of free campaigning in seats where a party is unlikely to make an electoral breakthrough (Not Held not Target) is evidently much lower than in other seats for all parties. On the other hand, however, the differentiation in intensity between target seats and those that are 'safe' (Held not Target) is tiny. Political circumstances may explain this a little in the case of the Labour Party. The party was unpopular and defending gains won after three election victories. In that sense, safe seats may not have been perceived as such by those offering the free effort.

In the case of the Conservative Party, however, the lack of differentiation is more difficult to explain, particularly given its relative popularity prior to the election. Yet it may reflect a longer term problem in the party, whereby electoral efforts are often misdirected at safer seats-especially where the central party is unable to deploy resources more effectively. Overall, then, the Conservatives enjoyed the highest level of free campaigning, but that advantage was tempered through strong targeting by the Liberal Democrats and, to an extent, seemingly excessive effort by the Conservatives in their safe seats. Of course, strong efforts in safe seats would be unlikely to damage the Conservative cause, but would represent a missed opportunity to focus efforts more effectively given the limited resources available, overall.

\section{The electoral impact}

To assess the relative electoral impact of candidate spending and free district level campaigning, we include both candidate spending data and the free campaigning index from the election agent survey in a single analysis. We create a model which regresses the impact of these two variables on the share of the vote in 2010, while 
controlling for the share of that party's vote in $2005^{7}$ and whether the party was fielding an incumbent candidate. Controlling for previous vote share through the use of a lagged endogenous variable is a widely used technique which introduces a dynamic specification into the model. The approach has a number of advantages. First, it allows us to capture factors affecting the change in electoral performance which is a much more meaningful gauge of effectiveness than simple 2010 vote share. Secondly, it captures the effect of a variety of other factors which are correlated with the underlying level of performance of each party (such as the demographic profile of the electorate). Thirdly, it captures the effects of previous campaigns at earlier elections. In sum, though we are not concerned with the value of the lagged endogenous variable itself, its use generates a more conservative picture of any campaign effects. We also control for personal incumbency as there is ample evidence to suggest that this had an independent impact in 2010 (Johnston et al., Forthcoming). The inclusion of vote share at the previous election not surprisingly has a significant and very substantial effect on model fit because the geography of voting for a party tends to be consistent across a series of elections, varying only in its relative topography. But it also serves to illustrate that where effects are found, they are likely to be robust. We operationalise our model using OLS.

The first analysis (Table 5) uses candidate spending during the Short campaign period, while the second (Table 6) uses the aggregate expenditure of candidates over the whole regulated period (Long plus Short campaigns). In both, we are seeking, first, to assess if candidate spending and free district campaigning each have independent effects. If they do, it suggests that factors not captured by candidate spending have electoral effects. If that is the case, it would suggest that disparities in spending can be offset to a degree by the level of free campaigning. And, if both candidate spending and free campaigning have independent effects, we can then compare their relative effects using the standardised beta coefficients.

The results vary across the three parties. In the case of the Conservatives, the findings are clear. Candidate spending over both regulated periods yielded electoral payoffs, while free campaigning had no impact in either model. This may be surprising in one sense-after all, the Conservatives had the highest levels of free campaigning overall and the highest levels in target seats. However, the relative lack of impact may be explained first by relatively poor targeting. Thus, while

\footnotetext{
${ }^{7}$ This analysis, like all of the others reported here, excludes the 18 Northern Ireland constituencies plus that being defended by the Speaker (where the parties traditionally do not field candidates) and Thirsk and Malton, where the election was held later (under different spending limits) because of the death of a candidate during the Short campaign period. Boundary revisions took place in England and Wales between 2005 and 2010 and so these are notional 2005 vote shares in England and Wales, but not in Scotland, where the boundaries were unchanged.
} 
Table 5. The electoral impact of candidate spending and free district campaigning (Short campaign spend)

\begin{tabular}{|c|c|c|c|c|c|c|c|c|c|c|c|c|}
\hline & \multicolumn{4}{|c|}{ Conservative $(n=281)$} & \multicolumn{4}{|c|}{ Labour $(n=384)$} & \multicolumn{4}{|c|}{ Lib Dem $(n=347)$} \\
\hline & $b$ & Std Error & Beta & Sig & $b$ & Std Error & Beta & Sig & $b$ & Std Error & Beta & Sig \\
\hline Constant & 2.741 & 0.646 & & ** & -8.175 & 1.004 & & $\star *$ & 2.889 & 0.848 & & $* *$ \\
\hline Vote 2005 & 0.966 & 0.022 & 0.925 & $* *$ & 0.872 & 0.023 & 0.840 & $* *$ & 0.662 & 0.036 & 0.658 & $* *$ \\
\hline Incumbent & 0.932 & 0.558 & 0.029 & n.s. & 2.270 & 0.689 & 0.066 & $\star *$ & 3.553 & 0.994 & 0.097 & $* *$ \\
\hline Free campaigning & 0.001 & 0.005 & 0.002 & n.s. & 0.046 & 0.011 & 0.079 & ** & 0.036 & 0.010 & 0.095 & $* *$ \\
\hline Candidate spending & 0.028 & 0.009 & 0.054 & ** & 0.025 & 0.012 & 0.047 & * & 0.060 & 0.010 & 0.184 & $\star *$ \\
\hline Adj. $R^{2}$ & & & & 0.955 & & & & 0.907 & & & & 0.864 \\
\hline
\end{tabular}

n.s. not statistically significant

Note: ${ }^{* *} p<0.01,{ }^{*} p<0.05$

Table 6. The electoral impact of candidate spending and free district campaigning (Short + Long campaign spend)

\begin{tabular}{|c|c|c|c|c|c|c|c|c|c|c|c|c|}
\hline & \multicolumn{4}{|c|}{ Conservative $(n=281)$} & \multicolumn{4}{|c|}{ Labour $(n=384)$} & \multicolumn{4}{|c|}{ Lib Dem $(n=347)$} \\
\hline & $b$ & Std Error & Beta & Sig & $b$ & Std Error & Beta & Sig & $b$ & Std Error & Beta & Sig \\
\hline Constant & 3.317 & 0.636 & & ** & -8.456 & 1.007 & & ** & 3.681 & 0.884 & & $* *$ \\
\hline Vote 2005 & 0.969 & 0.021 & 0.928 & $* *$ & 0.887 & 0.022 & 0.854 & $* *$ & 0.665 & 0.035 & 0.660 & $\star *$ \\
\hline Incumbent & 1.408 & 0.581 & 0.044 & * & 2.441 & 0.689 & 0.071 & ** & 3.061 & 0.985 & 0.083 & $\star \star *$ \\
\hline Free campaigning & -0.002 & 0.006 & -0.005 & n.s. & 0.051 & 0.011 & 0.088 & ** & 0.033 & 0.010 & 0.087 & ** \\
\hline $\begin{array}{l}\text { Candidate spending } \\
\text { Adj. } R^{2}\end{array}$ & 0.037 & 0.009 & 0.062 & $\begin{array}{l}* * \\
0.956\end{array}$ & 0.015 & 0.016 & 0.018 & $\begin{array}{l}\text { n.s. } \\
0.906\end{array}$ & 0.090 & 0.014 & 0.196 & $\begin{array}{l}* * \\
0.865\end{array}$ \\
\hline
\end{tabular}

n.s., not statistically significant.

Note: ${ }^{*} p<0.01,{ }^{*} p<0.05$ 
the Conservatives had strong levels of free campaigning in target seats, the same was also true in their safe seats. As a result, the overall effectiveness of their free campaigning will have been suppressed as any gains that would have been made in safe seats (particularly with that party being relatively popular) would be marginal. Secondly, of course, the data suggest that the impact of candidate spending was so great that any effects of free campaigning were significantly diminished.

In the case of Labour, the position is effectively reversed. Comparing free campaigning with candidate spending during the 'Short campaign' (Table 5), we find that both had a statistically significant impact on share of the vote, though spending only just reaches statistical significance. This, along with the standardised beta coefficients, suggests that free campaigning had a stronger effect. This is amplified when we look at spending over the entire regulated period (Table 6). Here, candidate spending had no statistically significant impact, while free campaigning continued to do so. Labour, of course, spent considerably less than the Conservatives (see Table 1), but what is apparent is that free campaigning appears to have compensated to some extent. The impact is confirmed when we compare the models first by including spending alone, and then by adding free campaigning. In both cases, $F$-tests confirm that the addition of free campaigning produces a statistically significant improvement in model fit.

Analysis of the Liberal Democrats also produces some interesting results. Again, both candidate spending and free campaigning had statistically significant effects (and in this case for both the Short campaign and the full regulated period). And, as with Labour, F-tests confirm the statistically significant improvement in the models generated by the inclusion of free campaigning. However, the order of the effects is perhaps unexpected. The Liberal Democrats have traditionally had significantly less money to spend and have relied on well-targeted efforts by grass roots activists (Cutts, 2006; Cutts and Shryane, 2006). We might expect, therefore, that the effects of free campaigning would be stronger than candidate spending. In fact, the reverse is true. The beta coefficients indicate that candidate spending had the stronger effect on Liberal Democrat vote share. Given that the Liberal Democrats spent substantially less than the Conservatives and somewhat less than Labour (see Table 1), the puzzle is why this occurred. The likely answer is effective targeting. As Table 2 shows, Liberal Democrat candidate spending in their target seats was broadly comparable with that of Conservative candidates in that party's targets. The Liberal Democrats had less money overall, but candidate spend was distributed very effectively. Of course, free campaigning by the Liberal Democrats was also effective. But once again, it was well targeted. As Table 4 shows, free campaigning by the Liberal Democrats in target seats was broadly comparable with that of the Conservatives too.

Of course, it is very likely to be the case that high levels of free activity in a constituency are associated with high levels of spending (and vice versa), 
suggesting possible problems with collinearity. Certainly, the index of free campaigning correlates positively with the levels of spending for all three parties, though not perhaps as strongly as we might expect. ${ }^{8}$ Thus, to confirm the robust nature of our findings, we regressed levels of free activity on candidate spending during the Short campaign and during the whole regulated period. From this we took standardised residuals for each as measures of free campaigning independent of spending. We then re-ran the regression models using these standardised residuals instead of the normal indicator of free campaigning. The results are shown in the Appendix (Tables A4 and A5) and confirm the broad findings in Tables 5 and 6.

The models reported in Tables 5 and 6 demonstrate that campaign effort (indexed by both candidate spending and our 'free campaign' measure) does boost vote share. But can it do so sufficiently to change the pattern of party representation in Parliament (the parties' ultimate aim)? We can gain some idea by using the models to simulate election outcomes under different party campaigning assumptions. For both sets of models, we look at six different scenarios. In the first three scenarios, we assume that in every constituency all three parties' 'free campaign' efforts are at the same level as each party's least active constituency campaign in 2010, and we further assume that two of the three party candidates spend nothing on any of their constituency campaigns while the remaining party candidates spends $100 \%$ of their legal allowance in every seat. In the final three scenarios, we assume that the party candidates spend nothing on their campaigns anywhere, and that two of the three parties run 'free campaigns' in all seats at the level of their least active free campaign in 2010, while the remaining party's free campaign is at the level of its most active 2010 constituency campaign.

For each scenario, we estimate the parties' vote shares in every constituency, and hence the likely outcome in seats (Table 7). While somewhat extreme, in that each scenario assumes one party runs a full-tilt campaign everywhere, while its rivals make minimal efforts, this does give some impression of the range of likely effects. And they can be substantial. For instance, had Conservative candidates spent up to the limit everywhere in the Short campaign while facing minimal campaigns from their rivals, the models predict they would have won 337 seats in 2010 to Labour's 244 and the Liberal Democrats' 39 (enough for a

\footnotetext{
${ }^{8}$ The correlations between free campaigning and the regulated spending periods (Short and Short Plus Long) are: 0.470 and 0.464 for the Conservatives; 0.585 and 0.526 for Labour; and 0.555 and 0.585 for the Liberal Democrats, so little more than, at most, one-third of the variation in free campaigning can be associated with that in spending. Scatter plots show that in general for all three-parties constituencies with low spending levels also have low values on each of the free campaigning variables but there is much greater variation in the amounts of free campaigning mobilised in seats where spending levels are above average.
} 
Table 7. Predicting the effects of local campaigning on seat distributions

\begin{tabular}{|c|c|c|c|c|c|c|}
\hline Scenario & $\begin{array}{l}\text { Con } \\
\text { spend } \\
100 \%\end{array}$ & $\begin{array}{l}\text { Lab } \\
\text { spend } \\
100 \%\end{array}$ & $\begin{array}{l}\text { LD } \\
\text { spend } \\
100 \%\end{array}$ & $\begin{array}{l}\text { Con max. } \\
\text { free } \\
\text { campaign }\end{array}$ & $\begin{array}{l}\text { Lab max. } \\
\text { free } \\
\text { campaign }\end{array}$ & $\begin{array}{l}\text { LD max. } \\
\text { free } \\
\text { campaign }\end{array}$ \\
\hline \multicolumn{7}{|c|}{ 'Short campaign spend' models: Seats } \\
\hline Conservative & 337 & 288 & 293 & 308 & 237 & 290 \\
\hline Labour & 244 & 286 & 259 & 265 & 342 & 259 \\
\hline Lib Dem & 39 & 46 & 68 & 47 & 42 & 71 \\
\hline \multicolumn{7}{|c|}{ 'Combined campaign spend' models: Seats } \\
\hline Conservative & 344 & 292 & 285 & 298 & 231 & 293 \\
\hline Labour & 240 & 282 & 252 & 273 & 350 & 261 \\
\hline Lib Dem & 37 & 46 & 83 & 49 & 40 & 66 \\
\hline
\end{tabular}

Parliamentary majority). But had Labour candidates been the party spending up to the limit everywhere while its rivals remained quiescent, the party could, despite its national unpopularity, have hoped to draw almost even with the Conservatives in MPs elected, gaining 286 seats to the latter's 288. The simulations also show that the potential effects of 'combined' Long and Short campaign spending on the distribution of seats was larger than those for Short campaign spending alone, and that the effects of going from the least active 'free campaign' everywhere to the most active were greater than the effects of going from spending nothing to spending up to the hilt. This latter finding is particularly striking, as it suggests voluntary (and largely face-to-face) activity has greater campaign potential than money alone (which mainly contributes to more impersonal forms of campaigning, such as leafleting). Parties neglect their grassroots at their peril, and concentrating on building strong local networks of active members and supporters ${ }^{9}$ may yield greater electoral dividends than ensuring well-funded constituency campaigns alone.

Overall, these analyses suggest that candidate spending as a measure of campaign intensity is a very useful surrogate measure. But it does not capture a significant aspect of campaigns - that provided free through voluntary labour. And, most critically, for Labour and the Liberal Democrats where free campaigning was substantial in 2010 it had significant electoral effects, independent of candidate spending. These findings are not an isolated example. Using a different measure of campaign spending, Fisher (2011) shows that free campaigning has

\footnotetext{
${ }^{9}$ Fisher, Fieldhouse and Cutts (Forthcoming) show that parties rely not only on members for their voluntary labour, but also supporters (who are not members). Indeed, some $78 \%$ of Conservative, Labour and Liberal Democrat local parties recruited supporters to assist with their campaigns at the 2010 Election.
} 
had independent effects for these two parties in most elections from 1992 to 2005. The implications here are clear. To be sure, the Conservatives enjoyed a significant financial advantage over their rivals in terms of candidate spending and were successful to a degree in exploiting that advantage. However, the advantages enjoyed by the Conservatives were offset in part by the impact of free campaigning by Labour and the Liberal Democrats.

However, the results in Tables 5 and 6 do not paint an entirely full picture since, of course, campaigns do not occur in isolation-other parties are also campaigning in constituencies. Thus, the optimal outcome of any one party's campaign is not only to enhance its share of the vote, but also to damage that of other parties. A further analysis is therefore required, which includes constituencies where we have free campaigning scores and candidate spending data for all three parties. Inevitably, this results in a significant reduction in the number of available cases and so it is here, where we have only 98 of the 630 constituencies with full data on candidate spending and levels of free campaigning for the Conservatives, Labour and the Liberal Democrats. This reduction in the number of cases means that the analysis we conduct should inevitably be treated with some caution. However, the results discussed and shown in the Appendix (Tables A6 and A7) continue to support the findings that free campaigning produces independent electoral payoffs and that candidate spending does not tell the whole story when examining campaign effectiveness.

\section{Conclusions}

Measuring the intensity of constituency campaigns at British general elections in order to assess their electoral impact has become increasingly sophisticated, with multiple sources of data employed. The result has been that researchers can illustrate very clearly that campaigns can boost electoral performance, but that effective management of these campaigns is essential to maximise their impact. Inevitably, any measure will not capture all of the effects. The survey of election agents has difficulty capturing efforts more than a year prior to polling day (and there is plentiful evidence that a significant amount of activity takes place before then), while the analysis of candidate spending can only focus on spending during regulated periods when candidates are required to file a return. Nevertheless, the various sources of data present a convincing case that spending and other canvassing/campaigning activities during the period immediately preceding an election can make a substantial impact on a party's performance. By combining data (as we do in this article), we are therefore in a position to make a good assessment about the extent to which the level of spending by a candidate is core to understanding his or her electoral performance. Of course, no one could fight an election without money, nor with a trifling sum-it is very clear 
empirically that even the most token campaigns require some expenditure and that broadly speaking, better funded campaigns have strong potential to deliver electoral payoffs and indeed do so.

However, what this article shows is that level of spending does not capture all campaign effects, and that free volunteer labour can also have a significant impact (see also Fisher et al., Forthcoming). As we see in the cases of Labour and the Liberal Democrats, their financial disadvantage relative to the Conservatives was offset somewhat by both effective management of their resources though targeting, but also by the level of free campaigning. Somewhat intriguingly, this was not the case for the Conservatives. But this result may tell us more about the continuing relative inability of that party to direct resources at a local level effectively, than about the nature of Conservative free campaigning. In essence, money matters and better financially endowed candidates will generally perform better electorally. Even so, it is apparent from this article that a party can compensate for its relative poverty to an extent, through well-targeted and well-managed free campaign activity.

Such conclusions may give cause for cautious optimism to those concerned that election outcomes can be unduly influenced by financial disparity, since better financial endowment may not be automatically beneficial in electoral terms. But they also have regulatory implications. As we show earlier in the article, concern about the distorting effects of candidate spending have prompted an extension of the regulated period of spending for candidates. And indeed, Labour has previously called for the regulated period to be analogous to that at the national level (which is currently 365 days), if not longer. Yet, if candidate expenditure can be offset to an extent by free volunteer labour (which presumably would be something that a democracy would wish to encourage), there might be a case for rejecting such calls for an extended regulatory period, or even reducing the current one given that even in target seats, candidates did not, on average, come anywhere near to the spending cap (see Table 2). However, an alternative view would be that although spending can be offset by free campaigning, there is no guarantee that this will always be the case-especially where parties have limited manpower. Thus, it makes sense to continue to regulate as we currently do, but perhaps treat any proposals for extension more cautiously, given the costs of compliance for what are still voluntary organisations.

\section{References}

Clarke, H. D., Sanders, D., Stewart, M. C. and Whiteley, P. (2004) Political Choice in Britain, Oxford, Oxford University Press.

Clarke, H. D., Sanders, D., Stewart, M. C. and Whiteley, P. F. (2009) Performance Politics and the British Voter, Cambridge, Cambridge University Press. 
Clift, B. and Fisher, J. (2004) 'Comparative Party Finance: The Cases of France and Britain', Party Politics, 10, 677-699.

Cutts, D. (2006) 'Where We Work We Win: A Case Study of Local Liberal Democrat Campaigning', Journal of Elections and Public Opinion, 16, 221-242.

Cutts, D. and Shryane, N. (2006) 'Did Local Activism Really Matter? Liberal Democrat Campaigning at the 2001 British General Election', British Journal of Politics and International Relations, 8, 427-444.

Cutts, D., Johnston, R., Pattie, C. and Fisher, J. (2012) 'Laying the Foundations for Electoral Success: Conservative Pre-campaign Canvassing before the 2010 UK General Election', Journal of Elections, Public Opinion and Parties, 22, 359-375.

Denver, D. and Hands, G. (1997) Modern Constituency Electioneering: Local Campaigning at the 1992 General Election, London, Frank Cass.

Denver, D., Hands, G., Fisher, J. and MacAllister, I. (2003) 'Constituency Campaigning in Britain 1992-2001: Centralisation and Modernisation', Party Politics, 9, 541-559.

Fieldhouse, E. and Cutts, D. (2008) 'The Effectiveness of Local Party Campaigns in 2005: Combining Evidence from Campaign Spending and Agent Survey Data', British Journal of Political Science, 39, 367-388.

Fisher, J. (2010) 'Party Finance-Normal Service Resumed?' Parliamentary Affairs, 63, $778-801$.

Fisher, J. (2011) 'Legal Regulation and Political Activity at the Local Level in Britain'. In Ewing, Tham and Rowbottom (eds) The Funding of Political Parties, London, Routledge, pp. $110-123$.

Fisher, J. and Denver, D. (2008) 'From Foot-Slogging to Call Centres and Direct Mail: A Framework for Analysing the Development of District-Level Campaigning', European Journal of Political Research, 47, 794-826.

Fisher, J., Denver, D. and Hands, G. (2006) 'The Relative Electoral Impact of Central Party Co-ordination and Size of Party Membership at Constituency Level', Electoral Studies, 25, 664-676.

Fisher, J., Cutts, D. and Fieldhouse, E. (2011) 'The Electoral Effectiveness of Constituency Campaigning in the 2010 British General Election: The 'Triumph' of Labour', Electoral Studies, 30, 816-828.

Fisher, J., Fieldhouse, E. and Cutts, D. 'Members Are Not the Only Fruit: Volunteer Activity in British Political Parties at the 2010 General Election', British Journal of Politics and International Relations, Advance Access published on 30 January 2013, DOI: 10.1111/ 1467-856X.12011.

Jacobson, G.C. (1980) Money in Congressional Elections, New Haven, Yale University Press.

Johnston, R. and Pattie, C. (2006) Putting Voters in Their Place: Geography and Elections in Great Britain, Oxford, Oxford University Press. 
Johnston, R. and Pattie, C. (2007) 'Funding Local Political Parties in England and Wales: Donations and Constituency Campaigns', British Journal of Politics \& International Relations, 9, 365-395.

Johnston, R., Pattie, C., Cutts, D., Fieldhouse, E. and Fisher, J. (2011) 'Local Campaign Spending at the 2010 General Election and its Impact: Exploring what Wider Regulation has Revealed', The Political Quarterly, 82, 169-182.

Johnston, R., Pattie, C., Cutts, D., Fieldhouse, E. and Fisher, J. 'The Long and the Short of It: Local Campaigning at the British 2010 General Election', Political Studies, Advance Access published on 18 March 2013, DOI: 10.1111/1467-9248.12011.

Katz, J.N. and King, G. (1999) 'A Statistical Model for Multiparty Electoral Data', American Political Science Review, 93, 15-32.

Pattie, C. J. and Johnston, R. J. (2009) 'Still Talking, But is Anyone Listening? The Changing Face of Constituency Campaigning in Britain, 1997-2005', Party Politics, 15, 411-434.

Pattie, C. J., Johnston, R. J. and Fieldhouse, E. A. (1995) 'Winning the Local Vote: The Effectiveness of Constituency Campaign Spending in Great Britain, 1983-1992', American Political Science Review, 89, 969-983.

Tomz, M., Tucker, J. A. and Wittenberg, J. (2002) 'An Easy and Accurate Regression Model For Multiparty Electoral Data', Political Analysis, 10, 66-93.

Whiteley, P. and Seyd, P. (1994) 'Local Party Campaigning and Voting Behaviour in Britain', Journal of Politics, 56, 242-251.

\section{Appendix}

\section{Multi-party models}

When considering the potential negative effects of opponents' campaigning alongside the positive ones, a different methodological approach is required. For our single-party analyses, we used OLS regression. However, this technique is less suitable in analysing vote shares in multiparty elections-in such analyses, OLS has a number of flaws. For instance, it assumes that the vote share for each party is independent of the shares for the other parties. Yet, of course, that is not the case. If the vote share for Labour goes up, that of other parties must go down. OLS regression predictions are also unbounded which means that a model could theoretically predict a negative vote share or a vote share $>100 \%$. For these reasons, a number of scholars have used seemingly unrelated regression (SUR) to account for the properties of multiparty vote share data (Katz and King, 1999; Tomz et al., 2002; Cutts and Shryane, 2006; Cutts, 2006; Pattie and Johnston, 2009, Fisher et al., 2011). In order to overcome the problem of 
Table A1. Responses. The numbers of responses for each party in the agent survey by target status were as follows

\begin{tabular}{lllll}
\hline & All & Held not Target & Target & Not Target not Held \\
\hline Conservative & 287 & 120 & 56 & 111 \\
Labour & 388 & 128 & 75 & 185 \\
Liberal Democrat & 353 & $*$ & 50 & 303 \\
\hline
\end{tabular}

Table A2. Mean percentage of maximum spend by responses during Long and Short campaigns

\begin{tabular}{lll}
\hline$\%$ & Respondents & All constituencies \\
\hline Conservative & 37.2 & 38.1 \\
Labour & 22.5 & 25.6 \\
Liberal Democrat & 18.8 & 19.6 \\
\hline
\end{tabular}

Table A3. Principal components analysis of free campaigning index

Component

$\%$ of electorate canvassed

0.705

$\%$ of constituency covered by number takers

0.845

No. of polling day workers

0.826

Note: After varimax rotation. 1 component extracted.

unbounded predicted values, 2010 vote shares were converted into vote share ratios between parties using a logistic transformation.

SUR models are, therefore, constructed to examine the impact of candidate spending and free campaigning on party support in 2010. The first model focuses on campaigning during the Short campaign period. The second model uses aggregate candidate expenditure (Long plus Short campaigns). In both analyses, Labour is used as the reference alternative and the natural log of the vote share ratio between it and the Conservatives and the Liberal Democrats is taken. For completeness, we also examine the impact of candidate spending, incumbency and free campaigning (independent of spending produced through the residuals analysis above) on the Liberal Democrat-Conservative 2010 vote ratio, where the Conservatives are the denominator in the ratio-dependent variable. Where a party is the denominator in the ratio (Labour in the first two cases and the Conservatives in the last case), negative values of the vote share ratio reflect a relatively better performance for it compared with the other party. 
Table A4. The electoral impact of candidate spending and free district campaigning (Short campaign spend) (residual analysis)

\begin{tabular}{|c|c|c|c|c|c|c|c|c|c|c|c|c|}
\hline & \multicolumn{4}{|c|}{ Conservative $(n=281)$} & \multicolumn{4}{|c|}{ Labour $(n=384)$} & \multicolumn{4}{|c|}{ Lib Dem $(n=347)$} \\
\hline & $b$ & Std error & Beta & Sig & $b$ & Std error & Beta & Sig & $b$ & Std error & Beta & Sig \\
\hline Constant & 2.789 & 0.562 & & $\star *$ & -4.988 & 0.673 & & $* *$ & 5.522 & 0.620 & & $* *$ \\
\hline Vote 2005 & 0.966 & 0.022 & 0.925 & $\star *$ & 0.872 & 0.023 & 0.840 & $\star *$ & 0.662 & 0.036 & 0.658 & $\star *$ \\
\hline Incumbent & 0.932 & 0.558 & 0.029 & n.s. & 2.270 & 0.689 & 0.066 & $* *$ & 3.553 & 0.994 & 0.097 & $* *$ \\
\hline Free Campaigning & 0.023 & 0.196 & 0.002 & n.s. & 1.046 & 0.260 & 0.064 & $\star *$ & 0.830 & 0.224 & 0.079 & $* *$ \\
\hline $\begin{array}{l}\text { Candidate Spending } \\
\text { Adj. } R^{2}\end{array}$ & 0.029 & 0.008 & 0.055 & $\begin{array}{l}* * \\
0.955\end{array}$ & 0.049 & 0.011 & 0.093 & $\begin{array}{l}* * \\
0.907\end{array}$ & 0.077 & 0.010 & 0.236 & $\begin{array}{l}* * \\
0.864\end{array}$ \\
\hline
\end{tabular}

Note: ${ }^{*} p<0.01,{ }^{*} p<0.05$, n.s. Not statistically significant.

Table A5. The electoral impact of candidate spending and free district campaigning (Short + Long campaign spend) (residual analysis)

\begin{tabular}{|c|c|c|c|c|c|c|c|c|c|c|c|c|}
\hline & \multicolumn{4}{|c|}{ Conservative $(n=281)$} & \multicolumn{4}{|c|}{ Labour $(n=384)$} & \multicolumn{4}{|c|}{ Lib Dem ( $n=347)$} \\
\hline & $b$ & Std Error & Beta & Sig & $b$ & Std Error & Beta & Sig & $b$ & Std Error & Beta & Sig \\
\hline Constant & 3.139 & 0.541 & & $\star *$ & -4.451 & 0.684 & & $\star *$ & 6.235 & 0.645 & & $\star *$ \\
\hline Vote 2005 & 0.969 & 0.021 & 0.928 & $* *$ & 0.887 & 0.022 & 0.854 & $\star *$ & 0.665 & 0.035 & 0.660 & $* *$ \\
\hline Incumbent & 1.408 & 0.581 & 0.044 & * & 2.441 & 0.689 & 0.071 & $* *$ & 3.061 & 0.985 & 0.083 & $\star *$ \\
\hline Free Campaigning & -0.071 & 0.199 & -0.005 & n.s & 1.232 & 0.270 & 0.075 & $\star *$ & 0.741 & 0.220 & 0.071 & $\star *$ \\
\hline Candidate Spending & 0.036 & 0.009 & 0.060 & $\star \star$ & 0.053 & 0.015 & 0.064 & $\star \star$ & 0.113 & 0.014 & 0.247 & $\star \star$ \\
\hline Adj. $R^{2}$ & & & & 0.956 & & & & 0.906 & & & & 0.865 \\
\hline
\end{tabular}

Note: ${ }^{*} p<0.01,{ }^{*} p<0.05$, n.s. Not statistically significant. 
Table A6. SUR models: the impact electoral of free campaigning and candidate spending (Short campaign spend).

\begin{tabular}{|c|c|c|c|c|c|c|}
\hline \multirow[b]{2}{*}{$(n=98)$} & \multicolumn{2}{|c|}{ Con-Lab } & \multicolumn{2}{|c|}{ Lib Dem-Lab } & \multicolumn{2}{|c|}{ Lib Dem-Con } \\
\hline & $b$ & Sig & $b$ & Sig & $b$ & Sig \\
\hline Constant & -0.05 & & -0.45 & * & -0.40 & * \\
\hline \multicolumn{7}{|l|}{ Party spending } \\
\hline Labour candidate spending & -0.02 & * & -0.01 & * & 0.00 & \\
\hline Conservative candidate spending & 0.01 & * & 0.01 & * & -0.01 & * \\
\hline Lib Dem candidate spending & 0.00 & & 0.01 & * & 0.01 & * \\
\hline \multicolumn{7}{|l|}{ Incumbency } \\
\hline Labour incumbent candidate & -0.49 & * & -0.15 & & 0.34 & * \\
\hline Conservative incumbent candidate & 0.57 & * & 0.46 & * & -0.12 & \\
\hline Lib Dem incumbent candidate & -0.01 & & 0.55 & * & 0.56 & * \\
\hline \multicolumn{7}{|l|}{ Free Campaigning } \\
\hline Labour & -0.01 & & -0.05 & & -0.05 & \\
\hline Conservatives & 0.09 & $*$ & 0.02 & & -0.07 & * \\
\hline Liberal Democrats & 0.07 & & 0.16 & * & 0.09 & * \\
\hline$R^{2}$ & & 0.85 & & 0.87 & & 0.64 \\
\hline RMSE & & 0.04 & & 0.04 & & 0.03 \\
\hline
\end{tabular}

Note: Con-Lab/LD-Lab: Breusch-Pagan test of independence: $\chi^{2}(1)=48.229, \operatorname{Pr}=0.0000$. Dependent variables: Conservative-Labour vote share ratio 2010; Liberal Democrat-Labour vote share ratio 2010. LD/Con: Breusch-Pagan test of independence: $\chi^{2}(1)=30.038, \operatorname{Pr}=0.0000$. Dependent variables: Liberal Democrat-Conservative vote share ratio 2010 (Labour-Conservative vote share ratio 2010 identical to Con-Lab above and not reported). ${ }^{*} \mathrm{p}<0.05$.

Table A6 shows the impact of candidate spending and free campaigning (independent of spending as per the residual analyses in Tables A4 and Tables A5) during the Short campaign on the 2010 vote share ratios described above. Both equations also include control variables to account for where each party stood an incumbent candidate. All models have a high goodness of fit $\left(R^{2}\right)$, while the Breusch-Pagan test, which checks whether residuals were uncorrelated across equations, is highly significant. ${ }^{10}$ In the first two equations, Labour is the denominator in the ratio-dependent variable. Against both the Conservatives and the Liberal Democrats, Labour did better where they spent more money during the Short campaign period. This was offset somewhat by both the other main parties' spending. When compared against Labour, both Conservative and Liberal Democrat candidate spending improved both parties' electoral performance. While spending mattered, Labour's level of free campaigning did

\footnotetext{
${ }^{10}$ We would expect the residuals to be positively correlated. In those constituencies where one party is stronger than predicted by the model, at least one of the other parties must be weaker. This would result in large residual variances in both equations and makes the use of OLS regression techniques highly problematic. It therefore justifies our decision to use an SUR model.
} 
Table A7. SUR models: The impact electoral of free campaigning and candidate spending (Short + Long campaign spend)

\begin{tabular}{|c|c|c|c|c|c|c|}
\hline \multirow[b]{2}{*}{$(n=98)$} & \multicolumn{2}{|c|}{ Con-Lab } & \multicolumn{2}{|c|}{ Lib Dem-Lab } & \multicolumn{2}{|c|}{ Lib Dem-Con } \\
\hline & $b$ & Sig & $b$ & Sig & $b$ & Sig \\
\hline Constant & 0.30 & * & -0.15 & & -0.40 & * \\
\hline \multicolumn{7}{|l|}{ Party spending } \\
\hline Labour candidate spending & -0.03 & * & -0.03 & * & 0.00 & \\
\hline Conservative candidate spending & 0.02 & * & 0.01 & * & -0.01 & * \\
\hline Lib Dem candidate spending & -0.00 & & 0.02 & * & 0.02 & * \\
\hline \multicolumn{7}{|l|}{ Incumbency } \\
\hline Labour incumbent candidate & -0.72 & * & -0.37 & * & 0.35 & * \\
\hline Conservative incumbent candidate & 0.65 & * & 0.43 & * & -0.22 & * \\
\hline Lib Dem incumbent candidate & -0.03 & & 0.39 & * & 0.42 & * \\
\hline \multicolumn{7}{|l|}{ Free campaigning } \\
\hline Labour & -0.09 & & -0.10 & * & -0.01 & \\
\hline Conservatives & 0.13 & * & 0.06 & & -0.07 & * \\
\hline Liberal Democrats & 0.13 & * & 0.19 & * & 0.06 & * \\
\hline$R^{2}$ & & 0.82 & & 0.85 & & 0.68 \\
\hline RMSE & & 0.04 & & 0.04 & & 0.03 \\
\hline
\end{tabular}

Note: Con-Lab/LD-Lab: Breusch-Pagan test of independence: $\chi^{2}(1)=59.479, \operatorname{Pr}=0.0000$. Dependent variables: Conservative-Labour vote share ratio 2010; Liberal Democrat-Labour vote share ratio 2010. LD/Con: Breusch-Pagan test of independence: $\chi^{2}(1)=30.600, \operatorname{Pr}=0.0000$. Dependent variables: Liberal Democrat-Conservative vote share ratio 2010 (Labour-Conservative vote share ratio 2010 identical to Con-Lab above and not reported).

${ }^{*} p<0.05$.

not have a significant effect on its relative vote share. By way of contrast, both the Conservatives and particularly the Liberal Democrats did better against Labour where they ran intensive-free campaigns. In the third equation, negative coefficients indicate an increase in the Conservative vote compared with the Liberal Democrats because Conservative vote share is the denominator in the ratiodependent variable. When compared against the Liberal Democrats, both Conservative candidate spending and free campaigning had a significant positive impact on the Conservative vote. Yet this was somewhat offset by the Liberal Democrats' campaigning. Their relative vote share also increased where the candidate spent more and had stronger free campaigns.

In Table A7, we use candidate spending over both regulated periods (the Long and Short campaigns). Many of the findings revealed in the previous model hold here too. All parties benefited where candidates spent more money. The main difference is the effect of parties' free campaigning. Compared with the Conservatives, Labour-free campaigning continued to have no significant effect on party performance. Yet, the Conservatives did benefit, not only from their own intensive-free campaigning, but also from that of the Liberal Democrats. 
However, against the Liberal Democrats Labour did significantly better where they ran active free campaigns, although this was offset in part by the impact of Liberal Democrat free campaigning. The results suggest that this proved particularly potent against Labour but was slightly less effective against the Conservatives, who themselves improved their own vote against the Liberal Democrats in those seats where they engaged in more free campaigning.

Overall, the results in Tables A6 and Tables A7 are slightly different from those found in the main analyses in Tables 5 and 6. However, it is worth reiterating that while the data used in Tables 5 and 6 are representative, those in Tables A6 and Tables A7 are less so, being selected solely on the basis of data availability. Notwithstanding, the central message of the article remains clear-free campaigning in 2010 had clear and independent electoral effects compared with candidate spending. This helps explain why the Conservatives did not perform better in 2010 despite of their substantial financial advantage. In other words, the level of candidate spending does not tell the whole story when examining campaign effectiveness. 